\title{
Humerus kondil ve epikondil kırıkları
}

\section{Humerus condylar and epicondylar fractures}

\author{
F. Erkal Bilen
}

İstanbul Memorial Hastanesi

\begin{abstract}
Distal humerus kondil ve epikondil kırıkları fazla görülmemekle birlikte, bunların tedavisi oldukça zahmetli olmakta ve sıklıkla kaynamama, kötü kaynama, eklem sertliği veya instabilite ile sonuçlanabilmektedir. Bu komplikasyonların gelişmemesi için maksimum stabiliteyi sağlayan bir osteosentez ve erken harekete başlanması elzemdir. Distal humerus kırıkları bimodal dağılım göstermektedir: gençlerde yüksek enerjili, yaşılıarda düşük enerjili travma sonrası oluşmaktadır. Genç grup daha çok 12-19 yaş arası erkeklerden oluşmaktayken, yaşlı grup 80 yaş üzeri kadınlardan oluşmaktadır. Tedavi stratejisi yaş grubuna göre belirgin olarak değişmektedir. Daha önce birçok sınıflandırma tanımlanmış ve kullanılmıştır, ancak 2006 yılında Davies ve Stanley tarafından tanımlanan sınıflandırmanın, klinik kullanım açısından karmaşık kırıkların tedavisinde dahi karar vermeyi sağlayan tedavi algoritması oluşturmaya yardım edebildiği için, uygunluğu ispat edilmiştir. Bu kırıkların tedavisinde en iyi sonuçlar tecrübeli ellerde elde edilmektedir. $\mathrm{Bu}$ nedenle, öğrenme sürecinin başındayken tecrübeli bir cerrahın yardımı olmaksızın üstlenilmemelidir.
\end{abstract}

Anahtar sözcükler: humerus kırıkları, distal; dirsek; cerrahi
Although being relatively uncommon, condylar and epicondylar fractures of the distal humerus are very demanding and often result in nonunion, malunion, joint stiffness or instability. In order to prevent these complications, maximum stability provided by the osteosynthesis and early mobilization are of paramount importance. Fractures at distal humerus have bimodal age distribution: high energy injuries occur in the young, and low energy injuries occur in the elderly. While the young group consists mainly of male patients between $12-19$, the elderly group mostly of female patients older than 80 years of age. The treatment strategy differs significantly in different age groups. Many classification systems have been proposed and used previously; however, the classification system described by Davies and Stanley in 2006 has proved to be and validated clinically useful, as it provided a management algorithm enabling reproducible decision-making for the treatment even in complex distal humeral fractures. The best results are achieved in experienced hands; thus, treatment of these fractures should not be attempted at the beginning of the learning curve without supervision.

Key words: humeral fractures, distal; elbow; surgery
D istal humerus kırıkları sıklıkla karmaşık ve zor tedavi edilen kırıklar olarak karşımıza çıkmaktadır. Tedavide başarılı bir sonuç için bu bölgenin anatomisinin ve değişik kırık tiplerinin anlaşılması gerekmektedir. ${ }^{[1]}$

Humerus, distal ucunda genişler ve yassılaşır. En geniş olduğu yer, epikondiller arası mesafedir. Eklem, mediyal ve lateralde kalın kortikal kemiğin oluşturduğu iki kolona bağlıdır. Önde fossa coronoidea, arkada ise fossa olecrani, ekstansiyonda olekranon ve fleksiyonda koronoid çıkıntının hareket arkını kısıtlamasını önleyen anatomik girintilerdir. Mediyal kolon, humerus uzun ekseniyle yaklaşık $45^{\circ}$ açılanarak fleksör-pronator kas grubunun, lateral kolon ise yaklaşık $20^{\circ}$ açılanarak ekstansör kas grubunun yapışması için origoları oluşturmaktadır. Mediyal, lateral epikondiller ve distal humerusun eklem yüzeyi içermeyen posterior bölümü plak ve vida uygulaması için uygun bölgeleri içermektedir. Ancak özellikle posteriordan uygulanan vidalarda anterior veya distal eklem yüzeyine penetrasyon oluşmadığına dikkat edilmelidir.

\section{ETIYOLOJi}

Distal humerus kırıkları bimodal bir dağılım gösterirler: gençlerde yüksek enerjili, yaşlılarda ise düşük enerjili kırıklar olarak karşımıza çıkmaktadır. Distal humerus kırıkları tüm kırıkların \%5'ini, dirsek bölgesi kırıklarının ise \%30'unu oluşturur. ${ }^{[1]}$

- Illetişim adresi: Doç. Dr. F. Erkal Bilen, Maçka caddesi no: 3 Şişli, İstanbul Tel: 0532 - 2815001 Faks: 0212 - 2190843 e-posta: bilenfe@gmail.com

- Geliștarihi: 10 Ocak2014 Kabul tarihi: 10 Ocak 2014 


\section{SINIFLANDIRMA}

Distal humerus kırıklarında birçok sınıflandırma sistemi kullanılmaktadır. Distal humerus kırıklarının sınıflandırmasında sıkça kullanılanlardan biri AO (Association for Osteosynthesis) sınıflandırmasıdır. Ancak, AO sınıflandırması tedavide yönlendirici olmaması ve sınıflandırılamayan kırıkların çokluğu nedeniyle eleştirilmektedir.

2006 yılında tanımlanan diğer bir sınıflandırmanın daha güvenilir olması, gözlemciler arası farklı değerlendirme oranının azlı̆̆ı ve tedavide yön gösterici olması nedeniyle daha kullanışlı olduğu bildirilmiştir. ${ }^{[2]} \mathrm{Bu}$ sınıflandırmaya göre, esas olarak eklem dışı olan kırıklarda (Şekil 1) olekranon osteotomisi gerekmeksizin posterior yaklaşım kullanılarak açık yerleştirme ve içsel tespit önerilmektedir. Ağırııklı olarak eklem içi olan kırık grubunda ise (Şekil 2) olekranon osteotomisi kullanılarak açık yerleştirme ve içsel tespit önerilmektedir. Üçüncü grup olan eklem kırıklarında (Şekil 3); eğer hasta fit ve aktif ise olekranon osteotomisi (Şekil 4) ve içsel tespit, yaşו, osteopenik veya artritik ise total dirsek artroplastisi önerilmektedir.

\section{Epikondil kırıkları}

Epikondil kırıkları, üzerine yapışan adale gruplarının traksiyonu sonucu yer değiştirme gösterebilir. Mediyal

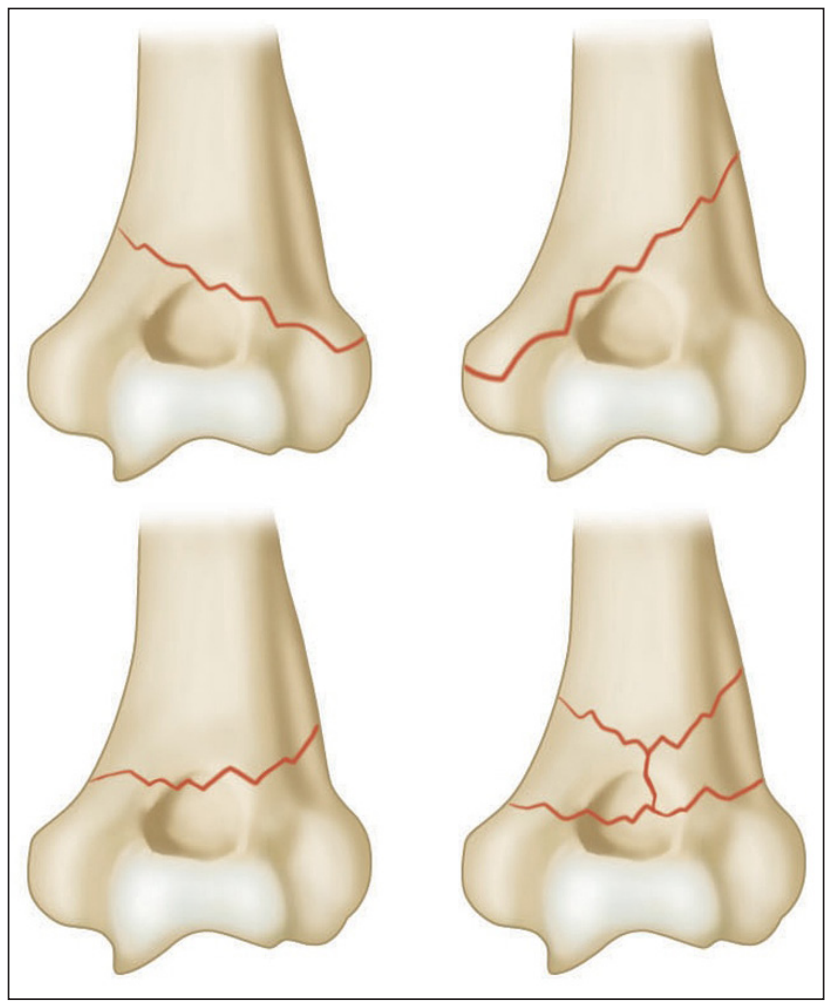

Şekil 1. Eklem dışı kırıklar. epikondile fleksör-pronator grup, lateral epikondile ise ekstansör-supinator grup adaleler yapışmaktadır. Epikondil kırıklarının iyileşmesi sağlanamadığı durumlarda dirsek instabilitesi gelişebilmektedir. Yukarıdaki sınıflamaya göre epikondil kırıkları genellikle birinci grupta yer almaktadır.

\section{Kondil kırıkları}

Humerus kondil kırıkları eklem hattına uzanan kırıklardır. Eklem yüzeyini ilgilendirdikleri için tedavi seçimi buna göre olmalıdır. Kondil kırıkları yukarıdaki sınıflamaya göre genellikle ikinci, bazen de üçüncü grupta yer almaktadır.

\section{DEĞERLENDIRME}

Humerus kondil ve epikondil kırıklarının değerlendirilmesinde ilk prensip, diğer tüm travmalarda olduğu gibi dirseğin cilt durumu, distal dolaşımı görüldükten sonra, duyu ve kaba motor muayenesini takiben iki yönlü grafisinin alınmasıdır. Kırık parçaların yönelim ve sayısının değerlendirmesinde gerekirse bilgisayarIı tomografiden faydalanılabilir (Şekil 5). Özellikle üç boyutlu rekonstrüksiyonlar deplasmanın yönünü, dolayısıyla repozisyonun nasıl yapılacağını belirlemede oldukça yararlı olmaktadır.

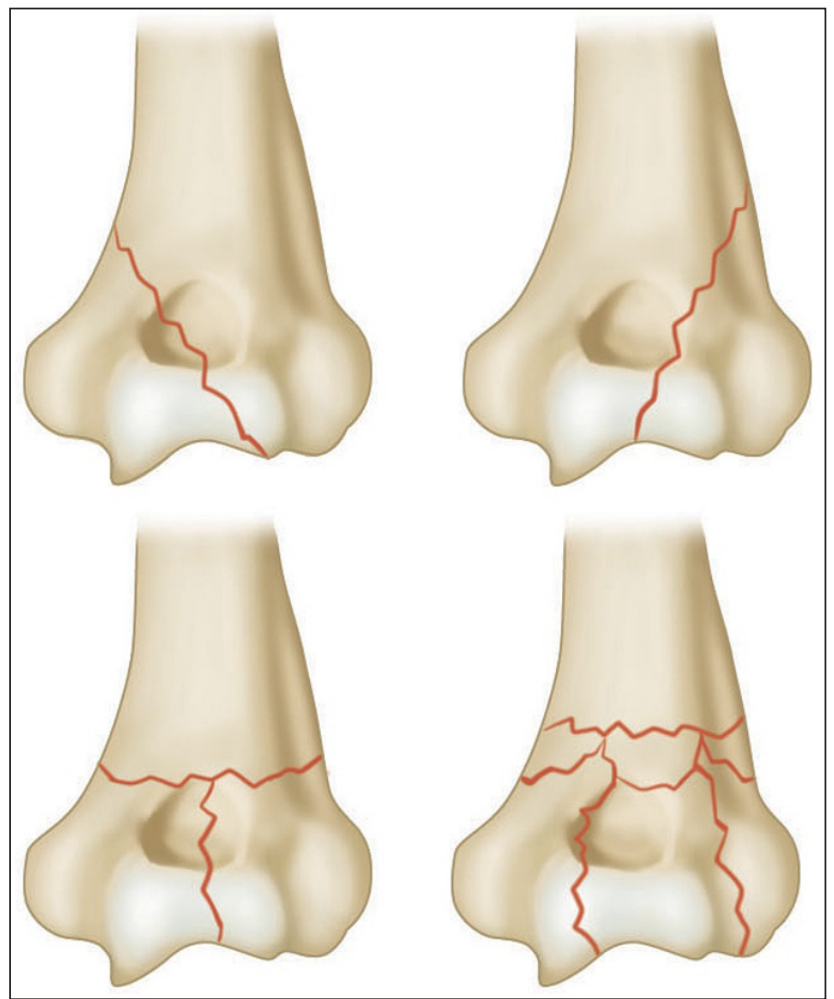

Şekil 2. Esas olarak eklem-içi kırıklar. 


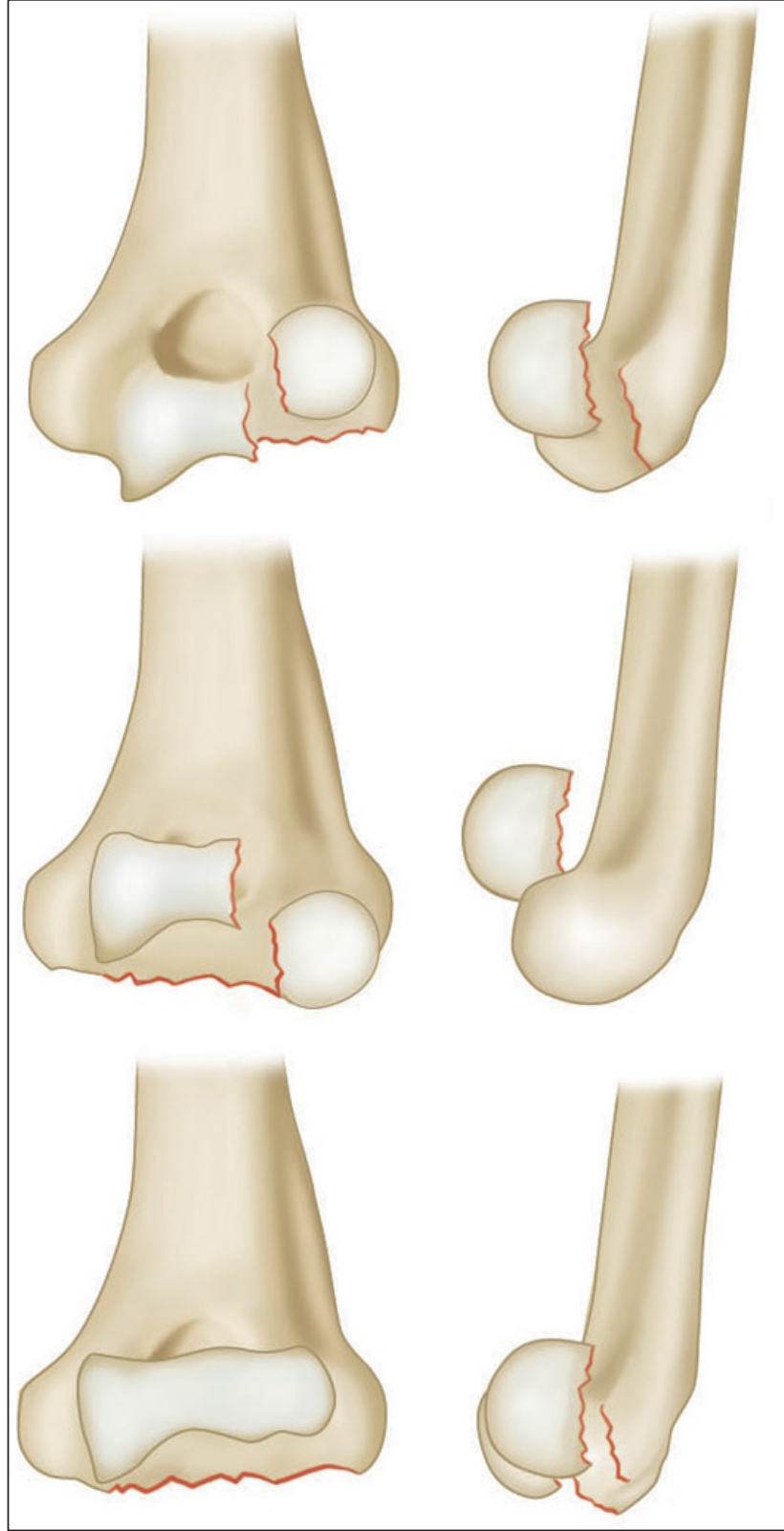

Şekil 3. Eklem kırıkları.

\section{TEDAVi}

\section{Konservatif tedavi}

Konservatif tedavi yer değiştirmemiş kırıklarda ya da anestezi alması kontrendike olan birçok komorbiditesi mevcut hastalarda uygulanmaktadır.

Yer değiştirmemiş bir mediyal epikondil kırığında dirsek $90^{\circ}$ fleksiyonda, ön kol pronasyonda ve el bileği $30^{\circ}$ fleksiyonda (bu pozisyon mediyal epikondile yapışan fleksör-pronator grubun yer değiştirici etkisini önleyecektir) immobilize edilmelidir.

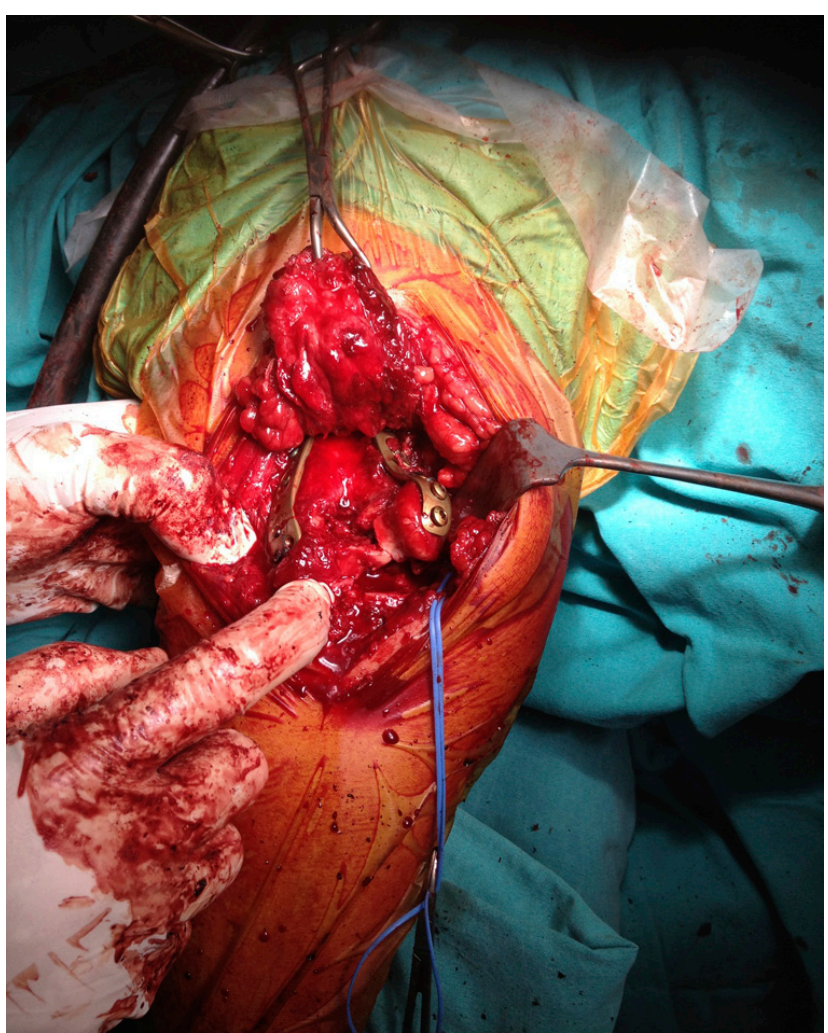

Şekil 4. Olakranon osteotomisi ile posterior yaklaşım. Eklem içi fragmanların net olarak ortaya konulabilmesi mümkün.

Yer değiştirmemiş lateral epikondil kırıklarında ise dirsek $90^{\circ}$ fleksiyonda, ön kol supinasyonda ve el bileği hafif ekstansiyonda (bu pozisyon lateral epikondile yapışan ekstansör-supinator grubu gevşetmeye yetecektir) immobilize edilir.

İmmobilizasyon süresinin olabildiğince kısa tutulması ve erken korumalı aktif harekete başlanması hareket kısıtlılığı gelişmesini önlemede çok önemlidir. Bunun için menteşeli breysler rahatlıkla kullanılabilir.

Kondil kırıklarında da, yer değiştirme yoksa kısa süreli immobilizasyonu takiben erken harekete başlamak, tedavi sonunda hareket açıklığı tam bir dirsek elde etmek için elzemdir. Ancak, bu kırıkların eklem içi kırıklar olduğu unutulmamalı ve çok az bir yer değiştirmenin dahi artroz ile sonuçlanabileceği unutulmamalıdır.

Gerek konservatif gerekse cerrahi tedavide iyi bir işlevsel sonuç, ancak erken aktif hareketle elde edilebilir.

\section{Plak ve vida uygulaması}

Dirsek bölgesi kırıklarının tedavisinde başarılı bir sonuç için stabil güvenilir bir tespit ve bunun olanak kıldığı erken aktif hareket elzemdir. Distal humerus bölgesinde stabil ve güvenilir bir tespit, ancak çift plak ve vida uygulanarak sağlanabilmektedir. Bunun için 


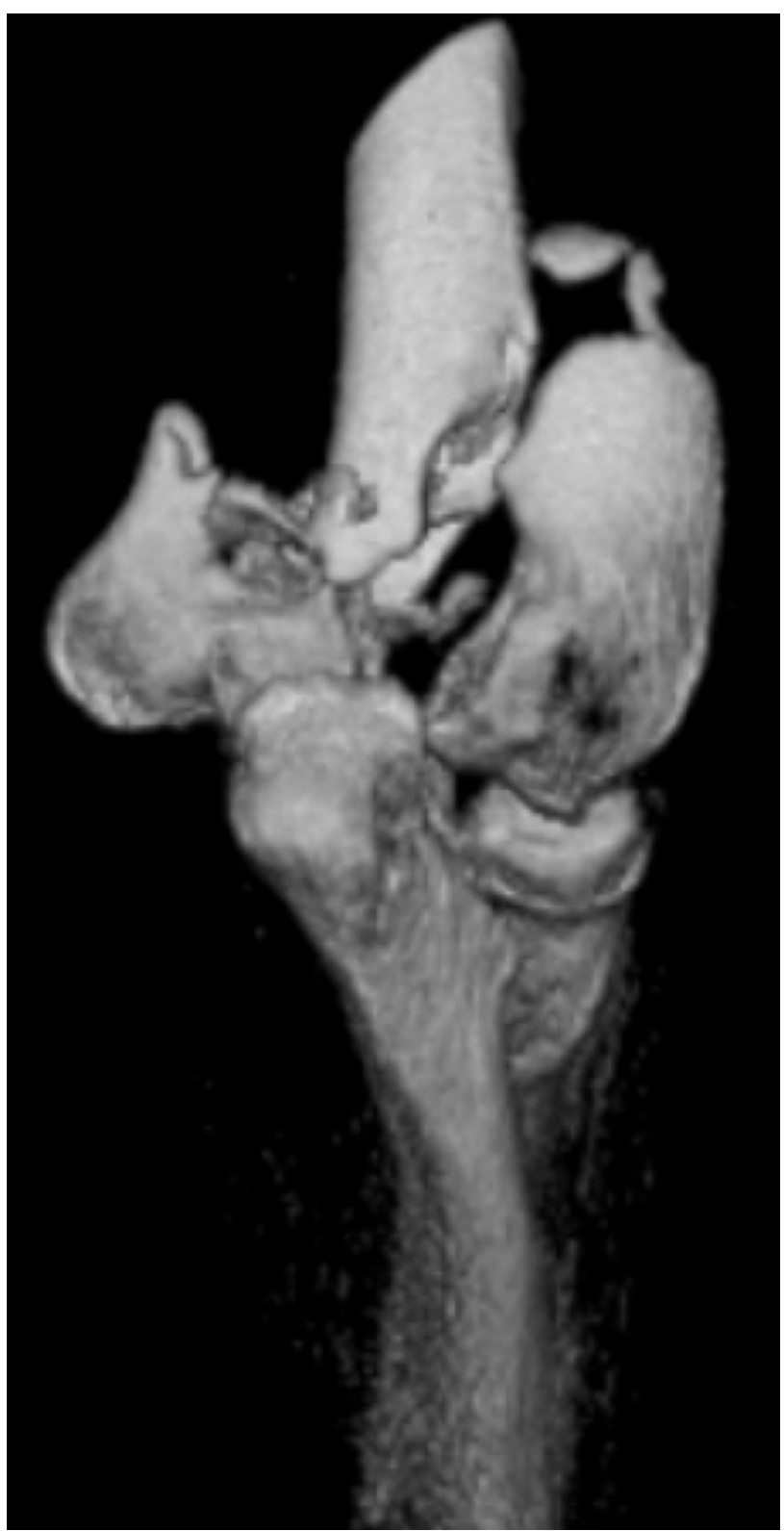

Şekil 5. Parçalı eklem içi distal humerus kırığının bilgisayarlı tomografi ile üç boyutlu rekonstrüksiyonu.

paralel ve 90-90 teknikleri sıklıkla uygulanmaktadır (Şekil 6-7). ${ }^{[3]}$ Biyomekanik olarak bu iki uygulama arasında belirgin üstünlük olmamakla birlikte, paralel plak uygulanması ve plak içerisinden uygulanan vidaların metafizde olabildiğince uzun boyda tutulup karşılıklı olarak içiçe geçmesinin en güvenilir tespiti sağladığı kabul edilmektedir. ${ }^{[4]}$ O'Driscoll plak uygulamasında maksimum stabiliteye ulaşılması için şu 8 prensibi öne sürmüştür:

1. Her vida plaktan geçmelidir.

2. Her vida karşı fragmanı tutmalıdır ve bu fragman karşı taraftan da plağa fikse edilmiş olmalıdır.
3. Distal fragmanlara olabildiğince fazla vida uygulanmalıdır.

4. Her vida olabildiğince uzun seçilmelidir.

5. Her vida olabildiğince fazla eklem fragmanını tutmalıdır.

6. Vidalar distal fragmanda karşıııklı olarak içiçe geçerek tüm humerusun stabilitesini arttıracak şekilde sabit açılı bir yapı oluşturmalıdır.

7. Plaklar her iki kolonda suprakondiler seviyede kompresyon oluşturacak şekilde uygulanmalıdır.

8. Plaklar kaynama olamadan önce kırılma ve bükülmeye karşı koyacak derecede sağlam ve sert olmalıdır.

\section{Dirsek hemiartroplastisi}

Dirsek hemiartroplastisi (yani, parsiyel protezi), son yıllarda, gençlerde görülen parçalı ya da kemik kayıplı distal humerus kırıklarının tedavisinde önerilmektedir. ${ }^{[5,6]}$

\section{Total dirsek artroplastisi}

Çok parçalı, özellikle osteoporoz zemininde gelişen distal humerus kırıklarında alternatif olarak total dirsek artroplastisi önerilmektedir. ${ }^{[7]}$ Distal humerus kırıklarında total dirsek artroplastisi için önerilen endikasyonlar şunlardır:

- yaşlı, beklentisi düşük hastalar,

- inflamatuvar artritli hastalar,

- patolojik kırıklı hastalar,

- düşük yaşam süresi öngörülen hastalar ve

- yetmiş yaş üzeri kaynamamalı (psödoartroz) hastalar.

Altmış beş yaş üzeri distal humerus kırıklarında içsel tespit ile total dirsek artroplastisini karşılaştıran ileriye dönük randomize bir çalışma, iki senelik takip sonunda artroplasti yapılan hastalarda daha iyi sonuç bildirmiştir. ${ }^{[8]}$

\section{TEDAVININ KOMPLIKASYONLARI}

Erken dönemde sinir yaralanması, yara problemleri ve enfeksiyon görülebilir. Geç komplikasyonlar ise eklem sertliği, kötü kaynama veya kaynamama olarak karşımıza çıkmaktadır. Cerrah eğer sinir dokusunun korunduğundan emin ise, ameliyat sonrası gelişen sinir lezyonları genellikle nörapraksi şeklindedir ve sıklıkla 2-3 ay içinde düzelir. Ancak sinir dokusu ekspoze edilmedi ve korunmadiysa erken eksplorasyon daha doğru olacaktır. Kötü kaynama ve kaynamamanın tedavisi genellikle cerrahidir ve oldukça zorludur. 


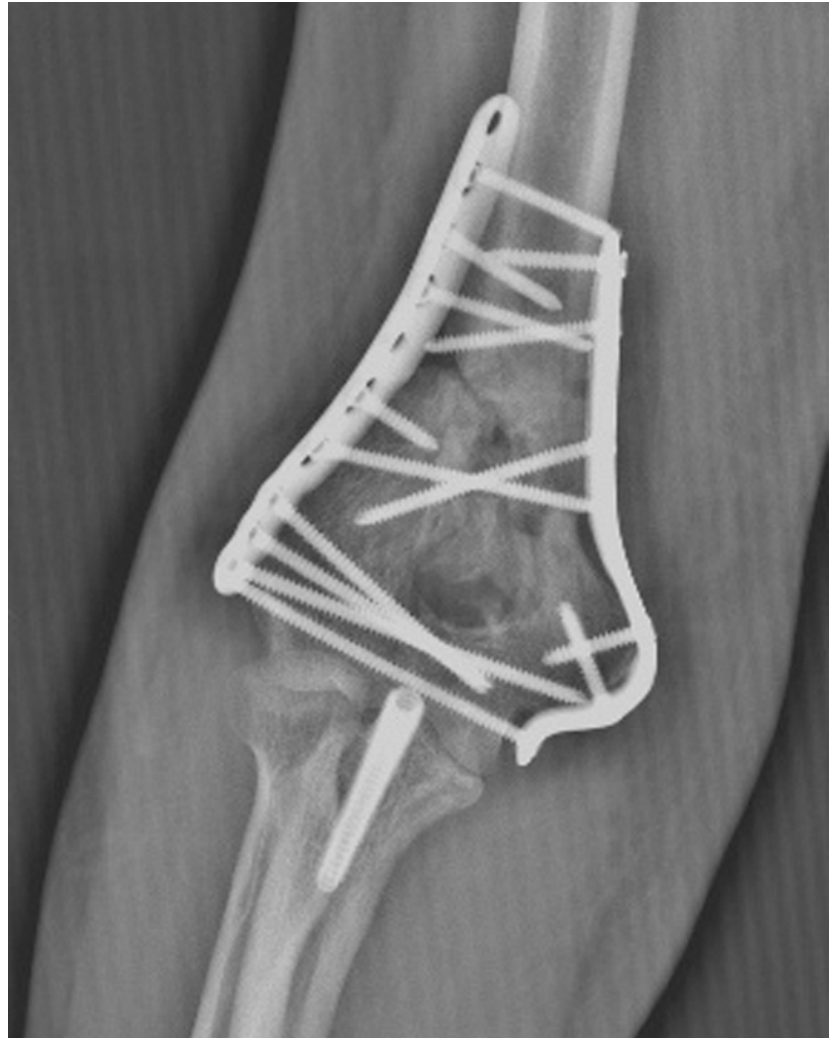

Şekil 6. Çift plak ile tedavi edilen bir distal humerus kırık olgusunun anteroposterior grafisi.

[9] Kaynamama her yaşta görülebilmekle birlikte, bu duruma en sık 5. dekadda (\%31) rastlandığı bildirilmiştir. ${ }^{[10]}$

\section{ÇIKARIM}

Distal humerus kırıklarının cerrahi tedavisi teknik olarak oldukça zordur ve ciddi cerrahi deneyim gerektirmektedir. Yeterli deneyime ulaşmadan önce uygulanan cerrahi tedavilerde sıklıkla kötü sonuçlar alınmakta ve revizyon cerrahileri gerekmektedir. Bu nedenle en doğru seçenek, bu hastaların cerrahi deneyim sahibi merkezlere sevkedilmesi olacaktır.

\section{KAYNAKLAR}

1. Adla DH, Stanley D. The Management Options for Adult Distal Humeral Fractures. In: Operative Elbow Surgery. Stanley D, Trail I, editors. China: Churchill Livingstone; 2012. p.253-265.

2. Davies MB, Stanley D. A clinically applicable fracture classification for distal humeral fractures. J Shoulder Elbow Surg 2006;15(5):602-8.

3. O'Driscoll SW. Fractures of the Distal Humerus: Plating Techniques. In: Operative Elbow Surgery. Stanley D, Trail I, editors. China: Churchill Livingstone; 2012. p.267-277.

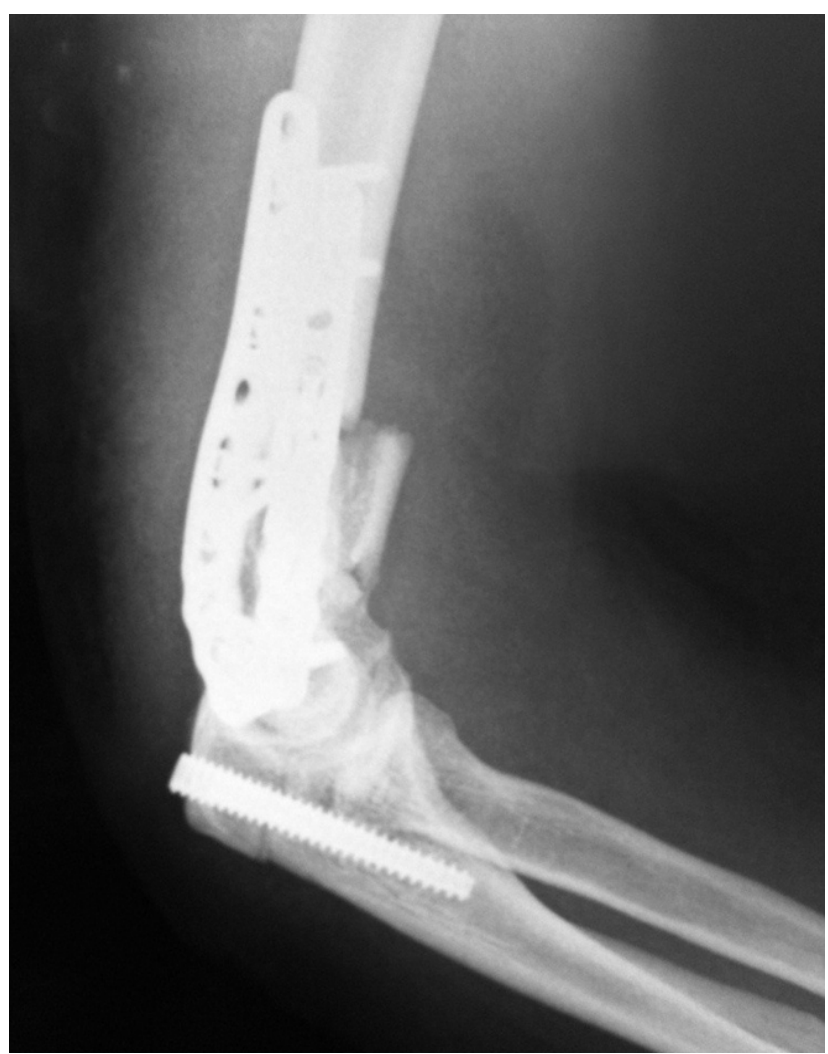

Şekil 7. Aynı olgunun lateral grafisi.

4. O'Driscoll SW. Optimizing stability in distal humeral fracture fixation. J Shoulder Elbow Surg 2005;14(1 Suppl S): 186S-194S.

5. Hughes J. Fractures of the Distal Humerus: Distal Humeral Hemiarthroplasty. In: Operative Elbow Surgery. Stanley D, Trail I, editors. China: Churchill Livingstone; 2012. p.279-289.

6. Smith GC, Hughes JS. Unreconstructable acute distal humeral fractures and their sequelae treated with distal humeral hemiarthroplasty: a two-year to eleven-year followup. J Shoulder Elbow Surg 2013; 22(12):1710-23. CrossRef

7. Mansat P, Bonnevialle N. Fractures of the Distal Humerus: Total Elbow Arthroplasty. In: Operative Elbow Surgery. Stanley D, Trail I, editors. China: Churchill Livingstone; 2012. p. 291-300.

8. McKee MD, Veillette $C J$, Hall JA, Schemitsch EH, Wild LM, McCormack R, Perey B, Goetz T, Zomar M, Moon K, Mandel S, Petit S, Guy P, Leung I.. A multicenter, prospective, randomized, controlled trial of open reduction-internal fixation versus total elbow arthroplasty for displaced intraarticular distal humeral fractures in elderly patients. J Shoulder Elbow Surg 2009;18(1):3-12. CrossRef

9. Ring D, Jupiter JB. Complex fractures of the distal humerus and their complications. J Shoulder Elbow Surg 1999;8(1):85-97.

10. Ali A, Douglas H, Stanley D. Revision surgery for nonunion after early failure of fixation of fractures of the distal humerus. J Bone Joint Surg Br 2005;87(8):1107-10. 